\title{
Association study between TRIM26 polymorphisms and risk of aspirin-exacerbated respiratory disease
}

\author{
JIN SOL LEE ${ }^{1 *}$, JOON SEOL BAE $^{1 *}$, JEONG-HYUN KIM $^{1}$, JASON YONGHA KIM $^{1}$, \\ TAE JOON PARK ${ }^{1}$, CHARISSE FLERIDA PASAJE ${ }^{1}$, BYUNG-LAE PARK ${ }^{2}$, HYUN SUB CHEONG $^{2}$, \\ AN-SOO JANG ${ }^{3}$, SOO-TAEK UH ${ }^{4}$, CHOON-SIK PARK ${ }^{4}$ and HYOUNG DOO SHIN ${ }^{1,2}$ \\ ${ }^{1}$ Department of Life Science, Sogang University, Seoul 121-742; ${ }^{2}$ Department of Genetic Epidemiology, \\ SNP Genetics, Inc., Seoul 153-801; ${ }^{3}$ Division of Allergy and Respiratory Medicine, Soonchunhyang \\ University Seoul Hospital, Seoul 140-743; ${ }^{4}$ Genome Research Center for Allergy and Respiratory \\ Diseases, Division of Allergy and Respiratory Medicine, Soonchunhyang University \\ Bucheon Hospital, Bucheon 420-767, Republic of Korea
}

Received November 25, 2011; Accepted January 5, 2012

DOI: $10.3892 / \mathrm{ijmm} .2012 .898$

\begin{abstract}
Aspirin-exacerbated respiratory disease (AERD) is a clinical syndrome that is characterized by nasal polyposis, general symptoms of asthma and sensitive response to nonsteroidal anti-inflammatory drugs (NSAIDs). Although the exact function of tripartite motif-containing 26 (TRIM26) still remains unknown, the gene functions in the immune response. Thus, we hypothesized that TRIM26 polymorphisms may affect aspirin-induced bronchospasm and explored whether the gene can be a marker for diagnosis of AERD. To investigate our hypothesis that TRIM26 may serve as a genetic marker for diagnosis of AERD, this study focused on demonstrating the associations between single nucleotide polymorphisms (SNPs) of the TRIM26 gene and AERD. We genotyped 18 polymorphisms of TRIM26 in a total of 189 asthmatics and examined their associations with the risk of AERD. We performed logistic analysis for obtaining P-values and regression analysis for demonstrating an association between the phenotype with $\mathrm{FEV}_{1}$ and the genotype. We observed no associations between polymorphisms in TRIM26 and the risk of AERD in both logistic and regression analyses. Although our results reveal a
\end{abstract}

Correspondence to: Professor Hyoung Doo Shin, Department of Life Science, Sogang University, Mapo-gu Sinsu-dong 1, Seoul 121-742, Republic of Korea

E-mail: hdshin@sogang.ac.kr

Dr Choon-Sik Park, Genome Research Center for Allergy and Respiratory Diseases, Division of Allergy and Respiratory Medicine, Soonchunhyang University Bucheon Hospital, Gyeonggido, Bucheon 420-767, Republic of Korea

E-mail:mdcspark@unitel.co.kr

${ }^{*}$ Contributed equally

Key words: aspirin-exacerbated respiratory disease, aspirin-tolerant asthma, tripartite motif-containing 26 , polymorphisms, haplotypes lack of association, the suggested functional role of TRIM26 makes it a putative candidate gene for AERD. Thus, replications in other populations using larger samples may provide valuable information for AERD etiology.

\section{Introduction}

Aspirin-exacerbated respiratory disease (AERD) is a disease that induces a severe clinical syndrome characterized by eosinophilic rhinosinusitis with nasal polyposis, general symptoms of asthma, and sensitive response upon uptake of non-steroidal antiinflammatory drugs (NSAIDs), including aspirin. The side effects of aspirin ingestion have been reported to be prevalent in 10-20\% of asthmatic patients (1-3). Although the mechanisms of AERD are not fully understood, abnormal secretion of eicosanoids including leukotrienes by blockage of the arachidonic acid pathway by aspirin is regarded as a significant factor of AERD pathophysiology (4-6). The COX pathway is involved in the immune response by releasing leukotrienes in immune cells, such as mast cells and eosinophils (7-10). Indeed, this process has been implicated in the etiology of nasal polyposis, a symptom that affects around two thirds of patients with AERD. Moreover, the polyps are filled with mast cells and eosinophils due to high level secretion of the proinflammatory cysteinyl leukotrienes (cysLTs) (11).

The leukotrienes are important molecules in recruitment of other immune cells to the inflammation site, an event that is established by signaling cascades. In line with this, the protein motifs used in protein-protein interactions and DNA-binding activity are remarkable. The tripartite motif-containing 26 (TRIM26) contains three zinc-binding domains, RING, B-box type 1 and B-box type 2, and a coiled-coil region (12). Although the exact function of TRIM26 still remains unknown, the protein may function in DNA binding through its motifs. To date, Reymond et al (13) have suggested that the TRIM family have partially overlapping functions with that of cellular compartmentalization and protein-protein interaction, processes that play relevant roles in recruitment of other proteins. Moreover, 


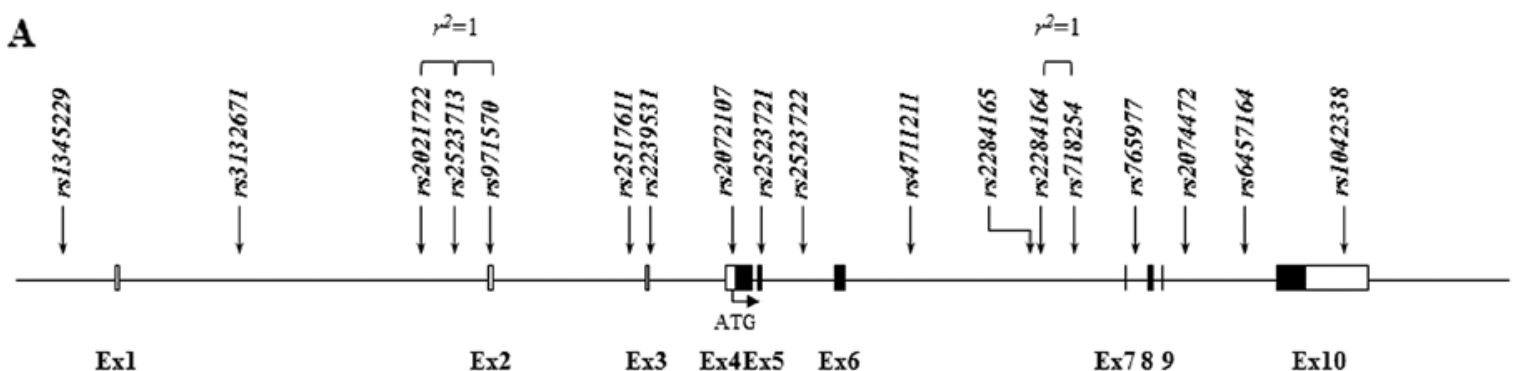

B

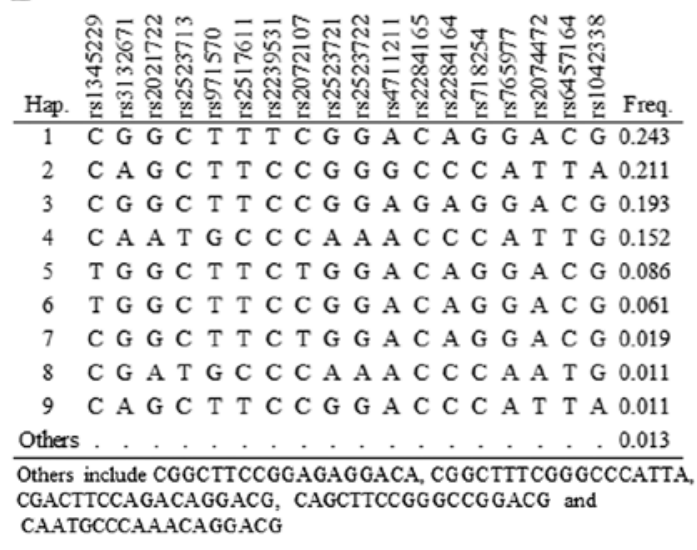

C

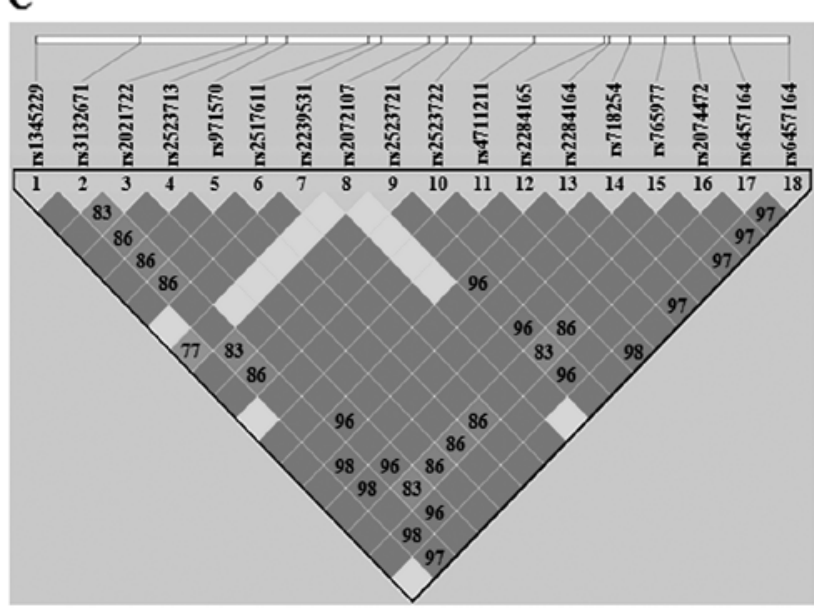

Figure 1. Schematic physical map, haplotypes and linkage disequilibrium (LD) plot of TRIM26. (A) Polymorphisms identified in TRIM26. Coding exons are marked by shaded blocks and 3'-untranslated region (UTR) by white blocks. The LD coefficients $\left(r^{2}\right)$ are based on the genotypes of Korean samples. (B) Haplotypes of TRIM26 in the Korean population. Only those with frequencies over 0.05 are shown. (C) LD coefficients (ID'l and $r^{2}$ ) among the selected SNPs based on the genotypes of all the study subjects in this study $(\mathrm{n}=189)$.

with its localization in the human histocompatibility complex (MHC) class I region, TRIM26 is speculated to have a role in the immune response in relation to its predicted protein function.

As described above, TRIM26 may possibly affect the risk of AERD by mediating immune responses. Therefore, we hypothesized that the polymorphisms in TRIM26 may affect AERD susceptibility and we explored whether the gene can be a marker for diagnosis of AERD in a Korean asthmatic population.

\section{Subjects and methods}

Study subjects. The subjects used in the present study were recruited from the Asthma Genome Research Center comprising hospitals of Soonchunhyang, Chonnam, Chungbuk, the Seoul National and the Chung-Ang Universities in Korea. The diagnosis for all of the subjects was conducted following criteria for asthma according to the Global Initiative for Asthma (GINA) (14). Diagnosis of AERD was determined using a method that is slightly modified from our previous description (15). Additionally, we also performed aspirin challenge in subjects who have a history of aspirin hypersensitivity and those observed to have urticaria, nasal polyp and sinusitis. The AERD subjects are characterized with $20 \%$ or greater decreases in forced expiratory volume in $1 \sec \left(\mathrm{FEV}_{1}\right)$ or 15 to $19 \%$ decreases in $\mathrm{FEV}_{1}$ with nasoocular or cutaneous reactions. In contrast, the aspirin-tolerant asthma (ATA) group have a rate of $\mathrm{FEV}_{1}$ decline $<15 \%$ without extrabronchial nasal or skin symptoms. The diagnosis tests were performed with consent of all subjects and the study protocols were approved by the Institutional Review Board of each hospital.

Single nucleotide polymorphism (SNP) selection and genotyping . We selected candidate polymorphic SNPs from the National Center for Biotechnology Information (NCBI; build 36) and the International HapMap Project (http://hapmap.ncbi.nlm.nih. gov/) databases based on the frequencies in Asian population and linkage disequilibrium (LD) status. For the validation of AERD risk association, we genotyped 18 SNPs in the TRIM26 gene (Fig. 1A). Genotyping was carried out with $20 \mathrm{ng}$ of genomic DNA using TaqMan assay in the ABI PRISM 7900HT sequence detection system software version 2.3 (Applied Biosystems, Foster City, CA, USA) in 93 AERD cases and 96 ATA controls with the assessment of data quality by duplicate DNAs $(n=10)$.

Statistics. We calculated the LD in all pairs of biallelic loci using Lewontin's D' (ID'I) (16) and $r^{2}$ (Fig. 1). The PHASE algorithm (ver. 2.0) developed by Stephens et al (17) was used for inferring haplotypes. Associations of genotypes and haplotypes in the TRIM26 gene with AERD were calculated using logistic analysis adjusted for age, gender, smoking status, atopy and body mass index (BMI) as covariates. We also performed linear regression analysis to determine the differences in the rates of decline in $\mathrm{FEV}_{1}$ following aspirin challenge among the genotypes and haplotypes. Data were adjusted, managed and analyzed using Statistical Analysis System (SAS) version 9.1 (SAS Inc., Cary, NC, USA). 
Table I. Clinical characteristics of case and control subjects.

\begin{tabular}{|c|c|c|c|}
\hline Characteristics & AERD & ATA & P-value \\
\hline Number of subjects & 93 & 96 & \\
\hline Age (years), mean (range) & $44.39(17-73)$ & $45.79(15-77)$ & 0.497 \\
\hline Age of onset (years), mean (range) & $38.01(0-70)$ & $37.99(5-73)$ & 0.995 \\
\hline $\mathrm{BMI}\left(\mathrm{kg} / \mathrm{m}^{2}\right)$, mean $\pm \mathrm{SD}$ & $23.47 \pm 3.18$ & $24.41 \pm 3.29$ & 0.049 \\
\hline Blood eosinophil $(\%)$, mean \pm SD & $6.29 \pm 5.80$ & $4.88 \pm 4.19$ & 0.060 \\
\hline FVC $\%$, predicted, mean \pm SD & $89.90 \pm 14.74$ & $87.76 \pm 12.80$ & 0.293 \\
\hline $\mathrm{FEV}_{1} \%$, predicted, mean $\pm \mathrm{SD}$ & $86.63 \pm 16.74$ & $88.26 \pm 17.04$ & 0.509 \\
\hline $\mathrm{PC}_{20}$, methacholine $(\mathrm{mg} / \mathrm{ml})$, mean $\pm \mathrm{SD}$ & $4.23 \pm 7.18$ & $3.04 \pm 4.27$ & 0.193 \\
\hline Total IgE (IU/ml), mean \pm SD & $321.65 \pm 623.31$ & $309.54 \pm 426.04$ & 0.878 \\
\hline Decline after aspirin challenge, mean \pm SD & $23.61 \pm 14.48$ & $0.94 \pm 2.76$ & 0.001 \\
\hline Gender (male/female) & $32 / 61$ & $24 / 72$ & 0.156 \\
\hline Ex-smoker/current smoker (\%) & $15.63 / 9.38$ & $6.45 / 12.90$ & 0.219 \\
\hline Skin test (\% positive) & 61.46 & 56.99 & 0.532 \\
\hline ASA side effect ( $\%$ positive) & 26.67 & 8.42 & 0.001 \\
\hline Polyposis (\% positive) & 63.86 & 29.27 & 0.001 \\
\hline
\end{tabular}

Age indicates age at first medical examination. AERD, aspirin-exacerbated respiratory disease; ATA, aspirin-tolerant asthma; BMI, body mass index; FVC, forced volume vital capacity; $\mathrm{FEV}_{1}$, forced expiratory volume in $1 \mathrm{sec} ; \mathrm{PC}_{20}$, methacholine concentration causing $20 \%$ fall in FEV; ASA, acetylsalicylic acid (aspirin).

Table II. Allele information of TRIM26 used in this study.

\begin{tabular}{|c|c|c|c|c|c|c|c|}
\hline \multirow[b]{2}{*}{ SNP ID } & \multirow[b]{2}{*}{ Allele change } & \multirow[b]{2}{*}{ Frequency } & \multirow{2}{*}{$\begin{array}{c}\mathrm{TF} \\
\text { binding site }\end{array}$} & \multirow{2}{*}{$\begin{array}{l}\text { Splicing site } \\
\text { (ESE/ESS) }\end{array}$} & \multirow[b]{2}{*}{ miRNA } & \multicolumn{2}{|c|}{ HWE } \\
\hline & & & & & & AERD & ATA \\
\hline rs 1042338 & $\mathrm{G}>\mathrm{A}$ & 0.230 & - & - & $\mathrm{Y}$ & 0.197 & 0.102 \\
\hline rs1345229 & $\mathrm{C}>\mathrm{T}$ & 0.384 & $\mathrm{Y}$ & - & - & 0.483 & 0.144 \\
\hline rs2021722 & $\mathrm{A}>\mathrm{T}$ & 0.377 & - & - & - & 0.764 & 0.066 \\
\hline rs2072107 & $\mathrm{G}>\mathrm{A}$ & 0.388 & - & - & - & 0.636 & 0.144 \\
\hline rs2074472 & $\mathrm{G}>\mathrm{C}$ & 0.390 & - & - & - & 0.561 & 0.125 \\
\hline$r s 2239531$ & $\mathrm{~A}>\mathrm{C}$ & 0.386 & - & $\mathrm{Y}$ & - & 0.328 & 0.144 \\
\hline$r s 2284164$ & $\mathrm{C}>\mathrm{G}$ & 0.195 & - & - & - & 0.175 & 0.994 \\
\hline$r s 2284165$ & $\mathrm{~A}>\mathrm{G}$ & 0.214 & - & - & - & 0.066 & 0.049 \\
\hline$r s 2517611$ & $\mathrm{G}>\mathrm{A}$ & 0.164 & - & - & - & 0.202 & 0.040 \\
\hline$r s 2523713$ & $\mathrm{G}>\mathrm{A}$ & 0.168 & - & - & - & 0.190 & 0.060 \\
\hline$r s 2523721$ & $\mathrm{C}>\mathrm{T}$ & 0.104 & - & $\mathrm{Y}$ & - & 0.790 & 0.205 \\
\hline$r s 2523722$ & $\mathrm{C}>\mathrm{T}$ & 0.246 & - & - & - & 0.291 & 0.196 \\
\hline rs3132671 & $\mathrm{T}>\mathrm{C}$ & 0.167 & - & - & - & 0.171 & 0.040 \\
\hline$r s 4711211$ & $\mathrm{~T}>\mathrm{G}$ & 0.164 & - & $\mathrm{Y}$ & - & 0.202 & 0.040 \\
\hline rs6457164 & $\mathrm{C}>\mathrm{T}$ & 0.166 & - & - & - & 0.190 & 0.040 \\
\hline$r s 718254$ & $\mathrm{G}>\mathrm{A}$ & 0.167 & - & - & - & 0.202 & 0.060 \\
\hline$r s 765977$ & $\mathrm{G}>\mathrm{A}$ & 0.377 & - & - & - & 0.452 & 0.066 \\
\hline rs971570 & $\mathrm{C}>\mathrm{T}$ & 0.146 & - & $\mathrm{Y}$ & - & 0.603 & 0.257 \\
\hline
\end{tabular}

TF, transcription factor; ESE, exonic splicing enhancer; ESS, exonic splicing silencer; AERD, aspirin-exacerbated respiratory disease; ATA, aspirin-tolerant asthma; HWE, Hardy-Weinberg Equilibrium; Y, yes.

\section{Results}

In present study, we recruited a total of 189 subjects including 93 AERD patients as cases and 96 ATA patients as controls.
Among the diagnostic factors, airways decline after aspirin challenge showed obvious differences after comparing each group, with $23.61 \pm 14.48$ for the AERD cases and $0.94 \pm 2.76$ for the ATA group $(\mathrm{P}=0.001)$. The case group also showed a 


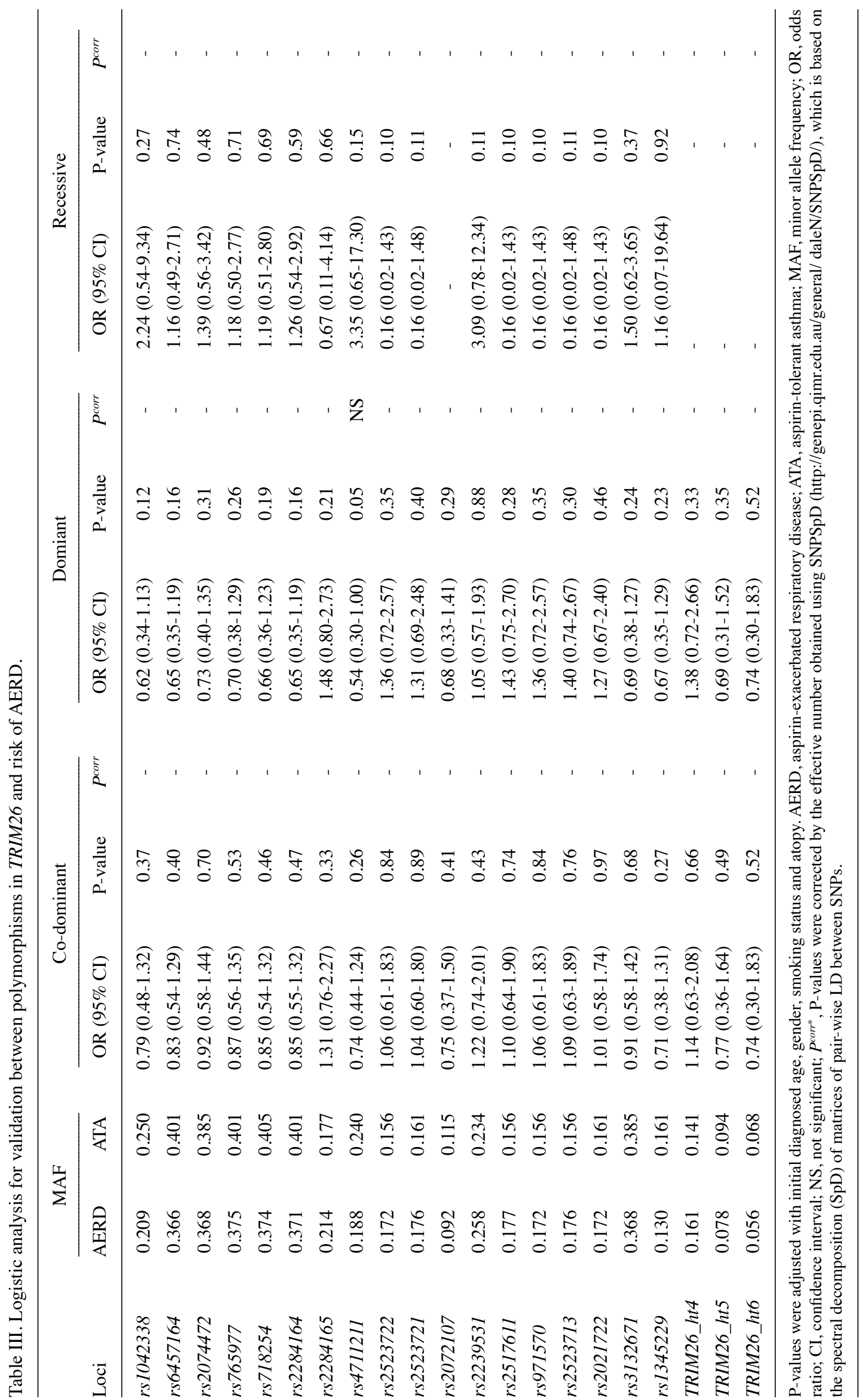




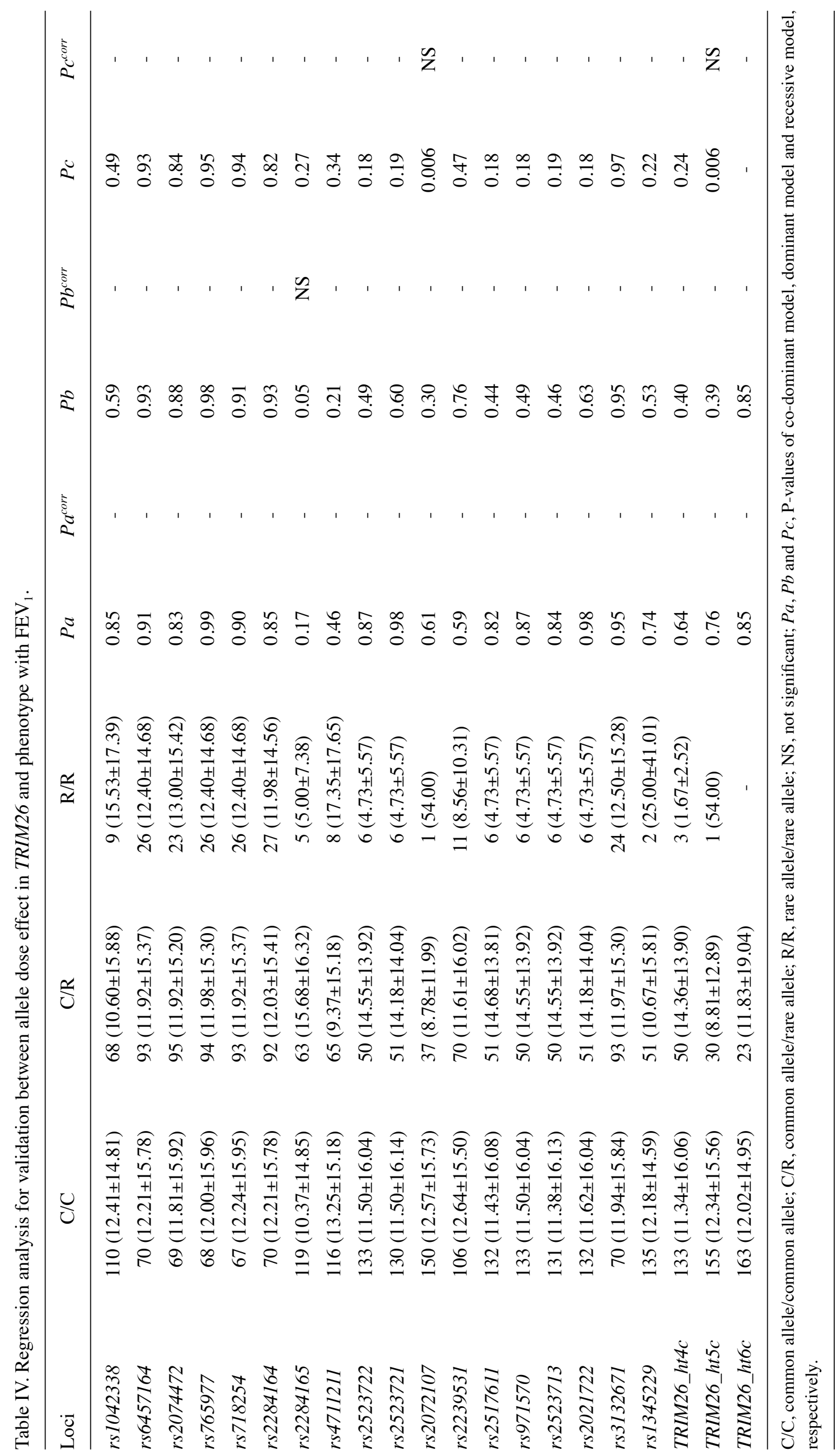


higher positive rate $(26.67 \%)$ of side effects after ingestion of ASA compared to the ATA control group (8.42\%). For other diagnostic factors of AERD, the positive rate of polyposis was observed to be $63.86 \%$ in AERD subjects and $29.27 \%$ in ATA asthmatics $(\mathrm{P}=0.001)$. Except for the three characteristics described above, other diagnostic factors of AERD showed no significant differences between the two groups. All the information of the study subjects are displayed in Table I.

For the analysis, we performed genotyping with 18 polymorphisms in a total of 189 subjects. Information about the 18 polymorphisms including allele change, minor allele frequencies (MAF), position and also the predicted function of polymorphisms using the web based software (snpinfo. niehs.nih.gov/snpfunc.htm) are listed in Table II. The prediction method shows that one polymorphism is associated with microRNA binding and another allele is included in the transcription binding site. In addition, among the polymorphisms in the exonic region, four SNPs affecting the splicing association site were identified using the exonic splicing enhancer (ESE) and exonic splicing silencer (ESS).

Initial logistic analysis revealed that the one polymorphism, $r s 4711211$, is associated with the risk of AERD. The variant has a $\mathrm{P}$-value of 0.05 and an odds ratio $(\mathrm{OR})$ of 0.54 with a $0.30-1.00$ confidence interval $(\mathrm{CI})$ in the dominant model. However, the signal disappeared after multiple testing corrections using the SNPSpD software. The other polymorphisms showed no associations with the risk of AERD in all three models of logistic analysis. Results of logistic analysis are displayed in Table III. Further regression analysis was conducted which focused on the $\mathrm{FEV}_{1}$ phenotype, and results are similar with the logistic analysis. Two SNPs, $r s 2284165$ and $r s 2072107$, showed associations with decline of $\mathrm{FEV}_{1}$ by aspirin provocation. Both SNPs show $\mathrm{P}<0.05$ in the initial analysis, which disappeared after multiple testing corrections. For the haplotype analysis, only one haplotype, TRIM26_ht5, shows significance in the regression analysis via a rare allele homozygote. However, the haplotype also failed to reach the threshold of significance after multiple comparisons. Results of the regression analysis are listed in Table IV.

\section{Discussion}

In the present study, we examined whether TRIM26 may serve as a genetic marker for the diagnosis of AERD. To test our hypothesis, we obtained P-values for the association between TRIM26 genetic variations and the risk of AERD. Although the significant signals disappeared after multiple testing corrections were performed, 3 of the 18 SNPs showed association signals in one of the two analyses. To date, a previous study has reported that MHC region polymorphisms, including TRIM27 from the TRIM gene family that is implicated in immuneassociated diseases, showed high association with systemic lupus erythematosus (SLE) (18). From analysis of 1,974 SNPs for finding association with SLE, 12 SNPs included in this investigation have been found to be associated with SLE (18). Although SLE and AERD occur in different sites of the human body, TRIM26 has been found to be expressed in various tissues including lung tissue (12). In line with this, although mechanisms of AERD are not fully understood, respiratory inflammation by eosinophil infiltration in airway tissues has been regarded as one of the causes of AERD. These research reports support an important role of TRIM26 in inflammation as a factor in AERD pathogenesis.

The TRIM gene family members have a RING domain and are suggested to have a role as intracellular molecular scaffolds (19). In the last decade, many researchers have reported that proteins linked with scaffolds are important in the pathogenesis of asthma $(20,21)$. In addition, it is known that protein scaffolds associated with the TNF receptor affect the cyclooxygenase pathway, one of the key mechanisms in AERD and in the production of prostaglandin E2 (22). The intracellular scaffold proteins form protein complexes that affect airway remodeling and are needed in triggering downstream signaling to recruit inflammation associated cells, such as mast cells (23-25). These reports suggest that TRIM26 may be associated with the risk of AERD and thus, more investigations on the role of TRIM26 in AERD are needed.

Another suggested functional role of TRIM26 is related to the ubiquitin protein ligase $(26,27)$. It has been demonstrated that ubiquitination is closely related with airway inflammation, as demonstrated by an experiment using the inhibitor of IкB ubiquitination in a mouse model (28). Moreover, our previous study showed that polymorphisms in ubiquitin-protein ligase $\mathrm{E} 3 \mathrm{C}(U B E 3 C)$ are significantly associated with pathogenesis of AERD (29). According to a previous study, IкB kinase ubiquitination in the classical NF- $\mathrm{\kappa B}$ activation pathway is important for inflammation and proteolysis of IкB, leading to translocation of NF- $\kappa B$ to nucleus. The signaling pathway triggers production of cytokines and chemokines and causes airway inflammation by recruiting eosinophils and lymphocytes $(28,30)$. Thus, although our results showed no association between polymorphisms in TRIM26 and risk of AERD, the reports described above support a possible association of TRIM26 in AERD pathogenesis. Furthermore, prediction methods show that four polymorphisms (rs2239531, rs2523721, $r s 4711211$ and $r s 971570$ ) in TRIM26 play certain roles in splicing-associated sites, thereby changing the protein expression pattern. Although the genetic distribution of Koreans is similar to that of Japanese and Chinese populations, it still differs from that of other populations. Thus, extrapolation of the present finding in other populations, such as Caucasians using larger sample sizes are needed.

In conclusion, the results of the present study show a lack of association between TRIM26 polymorphisms that are located in the MHC region and the risk of AERD in both logistic and regression analyses. However, the results may be valuable for further studies investigating the association between genes that are located in the MHC region and respiratory disease. Therefore, findings from this study may aid in a better understanding of the etiology of AERD and other bronchial diseases.

\section{Acknowledgements}

This study was supported by a National Research Foundation of Korea (NRF) grant funded by the Korea government (MEST) (nos. 2009-0080157 and 2010-0011206). This study was supported by a grant of the Korea Healthcare Technology R\&D Project, Ministry for Health, Welfare and Family Affairs, Republic of Korea (A010249). The DNA samples were generously provided by Soonchunhyang University, 
Bucheon Hospital Biobank, a member of the National Biobank of Korea, supported by the Ministry of Health, Welfare and Family Affairs, Republic of Korea.

\section{References}

1. Szczeklik A and Stevenson DD: Aspirin-induced asthma: advances in pathogenesis, diagnosis, and management. J Allergy Clin Immunol 111: 913-922, 2003.

2. Samter M and Beers RF Jr: Concerning the nature of intolerance to aspirin. J Allergy 40: 281-293, 1967.

3. Stevenson DD, Sanchez-Borges M and Szczeklik A: Classification of allergic and pseudoallergic reactions to drugs that inhibit cyclooxygenase enzymes. Ann Allergy Asthma Immunol 87: 177-180, 2001.

4. Szczeklik A and Stevenson DD: Aspirin-induced asthma: advances in pathogenesis and management. J Allergy Clin Immunol 104: 5-13, 1999.

5. Picado C: Aspirin-intolerant asthma: role of cyclo-oxygenase enzymes. Allergy 57 (Suppl 72): S58-S60, 2002.

6. Sampson A, Holgate S, Austen KF and Szczeklik A: Cyclooxygenase. Thorax 53: 719-720, 1998.

7. Curzen N, Rafferty $P$ and Holgate ST: Effects of a cyclo-oxygenase inhibitor, flurbiprofen, and an $\mathrm{H} 1$ histamine receptor antagonist, terfenadine, alone and in combination on allergen induced immediate bronchoconstriction in man. Thorax 42: 946-952, 1987.

8. Matsuoka T, Hirata M, Tanaka H, et al: Prostaglandin D2 as a mediator of allergic asthma. Science 287: 2013-2017, 2000.

9. Tanaka K, Ogawa K, Sugamura K, Nakamura M, Takano S and Nagata K: Cutting edge: differential production of prostaglandin D2 by human helper T cell subsets. J Immunol 164: 2277-2280, 2000.

10. Hirai H, Tanaka K, Yoshie O, et al: Prostaglandin D2 selectively induces chemotaxis in $\mathrm{T}$ helper type 2 cells, eosinophils, and basophils via seven-transmembrane receptor CRTH2. J Exp Med 193: 255-261, 2001.

11. Pawankar R: Nasal polyposis: an update: editorial review. Curr Opin Allergy Clin Immunol 3: 1-6, 2003.

12. Chu TW, Capossela A, Coleman R, Goei VL, Nallur G and Gruen JR: Cloning of a new 'finger' protein gene (ZNF173) within the class I region of the human MHC. Genomics 29: 229-239, 1995.

13. Reymond A, Meroni G, Fantozzi A, et al: The tripartite motif family identifies cell compartments. EMBO J 20: 2140-2151, 2001.

14. Bateman ED, Hurd SS, Barnes PJ, et al: Global strategy for asthma management and prevention: GINA executive summary. Eur Respir J 31: 143-178, 2008.
15. Park HS: Early and late onset asthmatic responses following lysine-aspirin inhalation in aspirin-sensitive asthmatic patients. Clin Exp Allergy 25: 38-40, 1995.

16. Hedrick PW: Gametic disequilibrium measures: proceed with caution. Genetics 117: 331-341, 1987.

17. Stephens M, Smith NJ and Donnelly P: A new statistical method for haplotype reconstruction from population data. Am J Hum Genet 68: 978-989, 2001.

18. Barcellos LF, May SL, Ramsay PP, et al: High-density SNP screening of the major histocompatibility complex in systemic lupus erythematosus demonstrates strong evidence for independent susceptibility regions. PLoS Genet 5: e1000696, 2009.

19. Borden KL: RING domains: master builders of molecular scaffolds? J Mol Biol 295: 1103-1112, 2000.

20. Walker JK, Fong AM, Lawson BL, et al: Beta-arrestin-2 regulates the development of allergic asthma. J Clin Invest 112: 566-574, 2003.

21. Moscat J, Diaz-Meco MT and Wooten MW: Signal integration and diversification through the p62 scaffold protein. Trends Biochem Sci 32: 95-100, 2007.

22. Wajant H, Henkler F and Scheurich P: The TNF-receptorassociated factor family: scaffold molecules for cytokine receptors, kinases and their regulators. Cell Signal 13: 389-400, 2001.

23. Lai $\mathrm{H}$ and Rogers DF: New pharmacotherapy for airway mucus hypersecretion in asthma and COPD: targeting intracellular signaling pathways. J Aerosol Med Pulm Drug Deliv 23: 219-231, 2010.

24. Bousquet J, Jeffery PK, Busse WW, Johnson M and Vignola AM: Asthma. From bronchoconstriction to airways inflammation and remodeling. Am J Respir Crit Care Med 161: 1720-1745, 2000.

25. Kopec A, Panaszek B and Fal AM: Intracellular signaling pathways in IgE-dependent mast cell activation. Arch Immunol Ther Exp (Warsz) 54: 393-401, 2006.

26. Freemont PS: RING for destruction? Curr Biol 10: R84-R87, 2000.

27. Jackson PK, Eldridge AG, Freed E, et al: The lore of the RINGs: substrate recognition and catalysis by ubiquitin ligases. Trends Cell Biol 10: 429-439, 2000.

28. Hirose K, Wakashin H, Oki M, et al: GS143, an IkappaB ubiquitination inhibitor, inhibits allergic airway inflammation in mice. Biochem Biophys Res Commun 374: 507-511, 2008.

29. Lee JS, Kim JH, Bae JS, et al: Association analysis of UBE3C polymorphisms in Korean aspirin-intolerant asthmatic patients. Ann Allergy Asthma Immunol 105: 307-312, 2010.

30. Wu W, Wang X, Zhang W, et al: Zinc-induced PTEN protein degradation through the proteasome pathway in human airway epithelial cells. J Biol Chem 278: 28258-28263, 2003. 